\title{
LXVI. Researches upon the heat developed in combustion, and in the condensation of vapours
}

\section{Count Rumford F.R.S.}

To cite this article: Count Rumford F.R.S. (1813) LXVI. Researches upon the heat developed in combustion, and in the condensation of vapours, Philosophical Magazine Series 1, 41:182, 434-444, DOI: $10.1080 / 14786441308638776$

To link to this article: http://dx.doi.org/10.1080/14786441308638776

曲 Published online: 27 Jul 2009.

Submit your article to this journal \lceil

Џ Article views: 2

Q View related articles $\sqsubset$ 
becomes gray like charcoal powder: in this way it assumed a blueish shade.

Experiment 20.-Deutoxide of Copper.

Its colour is a deep gray containing a little brownish red. On exposing it to heat, it becomes blacker, which proves that it has taken from the blue which has neutralized the red and the yellow.

\section{Experiment 21.-Deutoxide of Iron.}

It is of a gray colour, retaining very little of the brownish red. Heat produces blue, and its colour becomes of a purer gray, which by opposition makes the former appear redder.

\section{Experiment 22.-Peroxide of Antimony; Pearl Powder of Kerkringius.}

Its colour is a bright white, like white lead. When heated it takes a slight shade of dirty yellow or yellowish gray. We obtain a similar effect with the volatile oxide of antimony, but in a feebler degree.

LXVI. Researches upon the Heat developed in Comlustion, and in the Condensation of Vapours. Read before the French Institute on the 24th of February and 30th of November 1812. By Count Rum ford, F.R.S. Foreign Associate of the Imperial Institute of France, $\mathbb{E}^{*} . \mathscr{C O C}^{\circ}$.

[Continued from page 297.]

\section{$\S$ V. Heat developed in the Comlustion of Spirit of Wine and Alcohol.}

As the constituent parts of these inflammable liquids may be regarded as well determined, by the results of $M$. de Saussure's excellent work, I undertook a second time to examine them, with a view to what were the quancities of the heat which are developed during their combustion. I had begun this business five years ago; but after having made a considerable number of experiments, I abandoned it on account of the great difficulties which I met with; but the instant $I$ found means to make my apparatus more perfect I recommenced.

Before giving the details of my experiments, I dught to say a few words upon the difficulties which attended the enterprise, even since I possessed my new apparatus, and upon the means I used to surmount them. There were even dangers to which I was exposed, which it is necessary 
I should detail, in order to caution those who undertake the inquiry.

When I made experiments with highly rectified alcohol, and particularly with ether, I found it very difficult to prevent a remarkable pari of these volatile liquids from escaping in vapour from the mass of the liquid which remained in the lamp. I constructed a small lamp in the form of a round tobacco box, with a beak rising from the centre of the circular plate which forms the top: and upon this I fixed a small reservoir to contain cold water, intended to cool the beak, and prevent the heat from descending to the body of the lamp: but this precaution was not sufficient when I burnt ether, as I learned to my cost. Although the reservoir was twice as large in diameter as the lamp, and it was filled with cold water, this water was so heated in a few minutes that there was an explosion of ether in the state of vapour which tonk fire in the open air, and burned with a flame which touched the cieling, threatening to set fire to the house.

Rendered cautious by this accident, I constructed a new lamp, much smaller than the former: it was only an inch in diameter and three-fourths of an inch in depth, and its beak, which was only two lines in diameter, was threefourtlss of an inch high. In order to keep this small lamp conl while it was burning, it was placed in a small tub, and kept constantly submerged three lines below the upper extremity of its heak in a mixture of water and pounded ice. These precautions were sufficient to prevent explosions, but did not prevent the evaporation of the ether or of the alcohol. I was convinced of this fact by observing, that always, when I made two consecutive experiments without filling the lamp afresh, the alcotol constantly appeared weaker in the second experiment than in the first.

It was not difficult to account for this phanomenon: the most volatile, and consequently the most combustible parts of this liquid being dispersed in vapours in the interior of the lamp, found means to escape at the beak, with part of the liquid which had passed throngh the wick, leaving the alcohol which remained in the lamp sensibly weakened.

In prder to remerly this imperfection, I constructed a third lamp, which I have presented to the Class. It is made of copper, and has the form of a small cylindrical vase an inch and a half in diameter, and three fourths of an inch in herght, swelled a little at top and hermetically closed by a stopper of copper, which being ground with emery is wedged in to the neck of the vessel. 
This stopper is pertorated at its axis by a small vertical hole, which is wholly cinsed or partly openced, when requisite, by means of a small vice with a copper nut.

A small pipe about a line and a half in dameter, and two inches six lines in length, issues horizontally from the sides of this vase, and very near its bottom. At the distance of an inch and four lines from the vase this pipe forms an elbow, and afterwards ascending verticaliy forms the beak of the lanp.

This small pipe is very thin thronghout, except at its upper extremity, where it is thicker, in order to give it a form convenient for receiving a very small cylindrical extinguisher five lines high by three and a half in diameter, intended to close the beak hermetically, without touching or deranging the wiek at the instant the lamp ceases burnjing, and to keep it constantly shut when the lamp is not burning.

Without this precaution, in experiments made with ether, so great a quantity of this volatile liquid would escape in vapour, by the beak of the lamp, during the time taken up in weighing it, that there would be no way of determining the quantity burnt.

To support the beak of the lamp, it is stayed by two picces of copper wive, which proceed in a horizontal direction 10 jnin the body of the lamp to which they are soldered,

In order to keep this lamp constantly cold, as well as the liquid which it contains, it is placed in a smali tub and entirely covered, excepting the extremity of its beak and that of its mouth-piece, by a mixture of pounded ice and water.

When we weigh the lamp, it is taken out of its tub, and care is taken to wipe it well with dry linen before placing it in the scales.

When the lamp is lighted, we must not forget to open a little, and but a very little, the vice which forms its stopper, after it has burned two or three minutes; for without this precaution it mighis go out.

As the small horizomal pipe, by which the liyuid which is burnt passes from the reservoir of this lamp to reach its peak, is always filled with the liguid so as to have no communicarion with the vapour of the liquid which is dispersed in the urper part of the reservor, this vapour can no longer exciape by the beak of the lamp, as it did before I contrived the method of preventing it.

If I have given a very minute description of this lamp, it appeared to be necessary to spare thuse who wish to repeat 
my experiments, or to make others similar, all the diffeulties which I bad to surmount before discovermg the means of governing the combustion of inflamnable liquids which are very volatile.

As the apparatus which I used in my experiments is now well known, it will be easy to follow their detals and appreciate their results. I shall endeavour to describe them with precison, but at the same time as rapidly as possible.

After laying in a stock of common spirits of $x$ ine and alcohol of different degrees of purity, I determined with the greatest care their specific gravity at the temperature of $60^{\circ}$ (Fahrenheit), taking that of the 11 ater at the same temperature $=1000000$. I made choice of this temperature, in order to determine afterwards with more facility the quantities of water which each of these liquids ought to contain, according to the tables which were formed from the results of the experiments of M. Lowitz.

By the following table we shall see the specific gravity of each of these liquids, and the quantity of pure alcohol of Lowitz, and of water, which it contains.

\begin{tabular}{|c|c|c|c|}
\hline Kind of Liquid. & $\begin{array}{c}\text { Specific } \\
\text { Gravity at } \\
60^{\prime \prime} \text { F. }\end{array}$ & $\begin{array}{c}\text { Compositon. } \\
\text { Pure Alci\% } \\
\text { hol of } \\
\text { Lowitz. }\end{array}$ & Water. \\
\hline Alcohol at $42^{\circ} \ldots \ldots \ldots$ & 817624 & 0.9719 & 0.0821 \\
Alcohol of comnerce & 817140 & 08057 & $\mathbf{0 . 1 9 4 3}$ \\
Spirits of wine at $33^{\circ}$ & 853240 & 0.7788 & 0.2212 \\
\hline
\end{tabular}

Such are the results of the experiments which were made to determine the quantities of beat which these liquids furnish in their combuscion.

In three expcriments made with spirits of wine, the quantities of beat manifested were:

In the first ... 53.260 pounds of water at the freezing point, carried to ebullition.

In the second ... 51.7 97 pounds.

And in the third 52.855

Mean result... $\overline{52 \cdot 614}$ pounds.

As one pound of this liquid contains only 0.7788 pound of alcohol regarded as pure by Lowitz, the other parts $=0.2212$ pound, being water only which does not burn : in order to see how much water at the freezing point could be boiled by one pound of pure alcohol of Lowiz, we have only to divide the quantity which is the measure of the mean heat developed in the experiments with sprits of wine, by the fraction which expresses the quantity of the $\mathrm{E} \odot 3$ alcohul 
alcohol which is found in one pound of this liquic; ; then $s \frac{8}{0}: \frac{6}{4} 14=67.558$ pounds, which is the measure of the heat developed in the combustion of one pound of pure alcohol of Louitz, according to the mean result of the experiments made with spirits of wine.

In two experiments made with common alcohol, I had for the mean result 54.218 pounds of water boiled; and as this alcohol contained 0.8057 pound of pure alcohol, this will give for the measurement of the heat developed in the combustion of one pound of pure alcohol of Lowitz $\frac{34}{0.8} \cdot \frac{1}{5} \frac{1}{5} \frac{5}{7}$ $=67.293$ pounds of water heated $180^{\circ}$ Fahrenheit.

In three experiments made with alcohol at $42^{\circ}$ which had a specific gravity of $=817624$, I had as the mean result 61.952 pounds of water heated $i 80^{\circ} \mathrm{F}$. with the heat developed in the combustion of one pound of this liquid.

According to this result, one pound of pure alcohol of Lowitz onght to furnish a sufficiency of heal in its conbustion to raise the temperature of 67.57 pounds of water to $180^{\circ}$ of Fahrenheit, for it is $\frac{6}{0} \cdot \frac{1}{9} 9 \frac{5}{7} \frac{8}{8}=67 \cdot 101$.

On taking the mean between the results of the eight experiments which were made with these three alcoholic liquids, we shall have for the measure of the heat developed in the combustion of one pound of pure alcubol of Lowitz, 67.317 pounds of water at the temperature of freezing carried to ebullition.

It will be very interesting without doubt to know if this quantity of heat agrees with the quantities of combustible matters (carbon and hydrogen) which exist in this alcohol: this is precisely what we shall see.

According to the analysis of M. de Saussure, one pound of alcohol of Lowitz contains

$$
\begin{aligned}
& \text { Carbon ......... 0.4282 pound } \\
& \text { Free hydrogen ....... } 0.1018 \\
& \text { Vater........... } 0.4700
\end{aligned}
$$

Now, according to the estimate of Crawford, we shall have Pound of Water heated to $180^{\circ}$ Fahrenheit.

For the measure of the heat in the combus-? tion of 0.4282 pound of carben $\ldots \ldots \ldots\} 24.667 \mathrm{lbs}$.

And for the measure of that which is fur-? nished in the combustion of 0.1018 pound $\} 41.738 \mathrm{lbs}$. of hydrogen

$$
\text { Total...... 66.405 }
$$

The experiments yielded .......... $67 \cdot 317$

It is rare in so delicate an investigation to find so perfect an agreement between the results of the experiments and those of the calculation. 
in Combustion, and in the Condensation of Vapours. 439

$\$$ VI. Heat developed in the Combustion of sulphuric Ether.

I have already mentioned the difficulties which I overcame before being able to regulate the combustion of this substance in such a way as to render the results of my experiments regular and satisfactory; but I met with still further difficulties in the course of this delicate inquiry.

As alcohol is necessarily employed in making sulphuric ether, and as these two liquids may be united in any proportions, it is extremely difficult, if not impossible, to separate them entirely; and as both are colourless and limpid, either when mixed or separate, we can scarcely judge of the degree of purity of the ether, except by its specific gravity, and even in this way but very imperfectly.

The most highly rectified sulphuric ether which I could procure, and which I employed in my experiments, was prepared in M. Vanquelin's laboratory. Its specific gravity is 72834 at the temperature of $16^{\circ}$ Reaumur. As that which was employed by $M$. de Saussure in his analysis was only of the specitic gravity of 717 at the same temperature; by regarding the ether which I employed as being a mixture of the same degree of purity with that of $M$. de Saussure, and the pure alcohol of Lowitz having a specific gravity of 792, we shall find upon making a calculation, that the ether which I employed was a mixture of 85 parts of ether of the specific gravity of 717 , and 15 parts of pure alcohol of Lowitz of the specific gravity of 792 .

On burning this mixture under my calorimeter, after having brought my apparatus to the highest degree of perfection, I obtained the following results :

\begin{tabular}{|c|c|c|c|c|c|c|c|}
\hline \multirow[b]{2}{*}{ 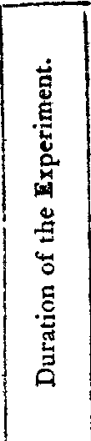 } & \multirow[b]{2}{*}{ 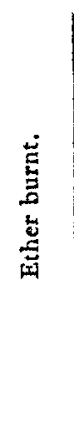 } & \multirow[b]{2}{*}{ 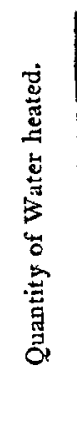 } & \multicolumn{2}{|c|}{$\begin{array}{l}\text { Temperature } \\
\text { of Water in the }\end{array}$} & \multirow[b]{2}{*}{ 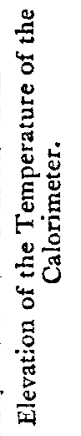 } & \multirow[b]{2}{*}{ 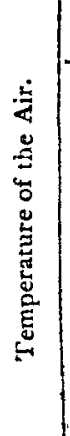 } & Result. \\
\hline & & & 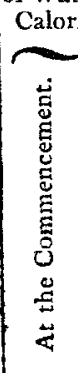 & 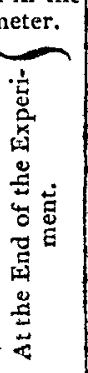 & & & 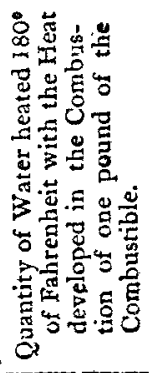 \\
\hline $\begin{array}{c}\text { mi.sec } \\
11 \\
11 \cdot 15 \\
9 \\
20 \\
22\end{array}$ & $\begin{array}{l}\text { gram. } \\
1.96 \\
2 \cdot 01 \\
2 \\
3.29 \\
3.06\end{array}$ & $\begin{array}{l}\text { gram. } \\
2781\end{array}$ & $\begin{array}{l}0 \mathrm{~F} \\
555^{10} \\
54 \frac{10}{4} \\
58.30 \\
56 \frac{30}{4} \\
561^{\circ}\end{array}$ & $\begin{array}{l}6530 \\
64 \% 0 \\
6928 \\
73 \frac{38}{4} \\
7270\end{array}$ & $\begin{array}{l}108^{\circ} \\
100^{\circ} \\
108^{\circ} \\
17^{\circ} \\
16^{\circ}\end{array}$ & $\begin{array}{l}60^{\circ} \\
60^{\circ} \\
60^{\circ} \\
61^{\circ} \\
642^{\circ}\end{array}$ & $\begin{array}{l}79 \cdot 996 \\
80.710 \\
80 \cdot 146 \\
79 \cdot 884 \\
80.784\end{array}$ \\
\hline & & Mean & Resul & a tive in & e Expe & ntents & $80 \cdot 304$ \\
\hline
\end{tabular}


Continuing to make use of the estimates of Crawford, for the quanities of beat developed in the combustion of hydrogen and carbon, we shall ste if these estumates are sufficient to account for the heat manitested in these five experiments.

As the ether employed was a mixture of 15 parts of pure alcohol of Lerwitz, and 85 parts of ether of the specific gravity of 317 at the temperature of $16^{\circ}$ Reammur, and consequentily sinilar to the ether analysed by M. de Saussure, we shall begin by determining the quantity of heat which ought to to be devcloped in the combustion of these fitteen parts of alcohol.

As M. de Sallinule has slown that in one pound of Lowitz's alcohol (of the specific gravity of 792) there are 0.4282 pound of carbon and 0.1018 pound of free bydrogen, we oumht to find in 0.15 pound of this same liquid, $0.06+23$ pound of carbou, and 0.01527 of free hvdrogen.

According to the estimate of $\mathrm{Ct}_{t}$ aw ford, 006423 pound of carbon ought to furmish a sufficiency of heat in its combustion to raise the cemperature of 3.7002 portods of water to $150^{\circ}$ Fah.: and 0.01527 prund of hydrogen ought to furnish enough to raise to the same temperature 6.2607 pounds of water; and these two quantitic of water making together 9.9699 pounds, is the measure of the quantity of heat which must be developed in the combustion of the 15 parts of alcobol which are found mixed with 85 parts of ether, in order to form the combustible liquid employed under the name of sulphuric ether in my experiments.

Now, as one pound of this mixed liquid has furnished in its combustion enough of heat to raise to $180^{\circ}$ of Fahrenheit co-304 pround of water; if we deduet from this mass the guantity of water which the 15 per cent. of alcohol mest heat $(=9 \cdot 9) 9)$, that which remains $(=70.3431$ pounks of water) will be the measure of the nuantity of heat developed in the combustion of 85 per cent. of cther of the gravity of $\pi 1 \pi$, which existsin this combustible liquid.

According to the analysis of sulphuric ether made by M. de Saussure, we ought to find in one pound of this liquicl (of the specific gravity of 717 )

Carbon ........................... 0.590 lb.

Free and combustible hydrogen $\ldots \ldots \ldots \ldots .0 .194$

Oxygen and hydrogen in the proportions

necessary to form water............ 0.216

.

Consequently, we ought to find in 0.85 pound of the 
in Combustion, and in the Condensation of Vapours. 441

same kind of ether, the following quantities of combustible substances; viz.

Carbon ...................... 0.5015 lb.

Free and combustible hydrogen.......... 0.1651

We shall now see if these quantities of combustible substances are sufficient to account for the heat which is manifesterl in our experiments.

The 0.5015 pound of carbon ought to furnish sufficient heat to raise 28.89 pounds of water to $180^{\circ}$ of Fahrenbeit; and the 0.1651 pound of hydrogen sufficient to heat $6 \mathbf{7} \cdot 64$ pounds to the same degree.

These two inasses of water form together 96.53 pounds; but we shall see that the quantity of heat furnished by the 85 parts of ether in the experiments camnot be greater than that which is necessary to heat 70.3431 pounds of water to $180^{\circ}$ Fahrenheit.

As the experiments have been made with the greatest care, and frequently repeated, and always with very uniform results; and as the estimates wbich we have adopted, with respect to the quantities of heat which are developed in the combustion of hydrogen and in that of carbon, have been confirmed so as to leave little doubt upon this subjccl: upon investigating the cause of the great difference between the quantity of heat actually developed in the combustion of the 85 parts of sulphuric ether burnt in the experiments which we have examined, and the quantity given by calculation, wé are'compelled, in my opinion, to admit that there is an error in the analysis of this liquid, and that it does not contain so much free and inflammable combustible matler as M. de Saussure ascribes to it.

As it seems to me to be much more probable that an error has been committed in determining the quantity of free hydrogei in this substance than in determining the quantity of carbon, I shall suppose with M. de Saussure that there is really in one pound of sulphuric ether (of the spceific gravity of 717) 0.59 of carbon; but instead of estimating the quantity of free hydrogen in this liquid according to the results of $M$. de Saussure, I shall adopt the estimate of Mr. Cruickshanks.

This excellent chemist concluded from his experiments, that in the vapour of sulphuric ether the carbon is to the bydrogen as 5 to 1 .

In the 0.85 pound of sulphuric ether (specific gravity 717) which were mixed with the 0.15 pound of alcohol, in order to form one pound of the mixed liquid employed in my experiments, there were 0.5015 pound of carbon; and 
dividing this number by 5 , we shall see that this carbon ought to be united with 0.1003 pound of free hydrogen, instead of being united with $0^{\cdot 1651}$ pound, as we shall supperse according to M. de Saussure.

Let us now see if, by adoping the analysis of Mr. Cruickshanks with respect to the hydrogen instead of that of M. de Saussure, the calculation will agree better with the experinert.

We have seen that the quantity of water heafed to $180^{\circ}$ Fahrenheit, which represents the quantity of heat which must be developed in the combustion of the 0.15 pound of alcohol, was .................. 9.9609 lbs.

And that the quantity answering to 0.5015 pound of carbon, which exists in the 0.85 of ether, was .................... 28.89

We shall for the present add that which answers to the combustion of 0.1003 pound of free combustible hydrogen, which, according to Mr. Cruickshanks, ought to be found united to this quantity of carbon in order to form the ether ......................41.123

These three quantities of water together are the theasure of the heat which must be devefoped in the combustion of ne pound of sulphuric ether of the kind employed in my experiments ...................... 79.9739

The mean result of five experiments was 80.304 .

This coincidence between the calculation and the experiment is doubiless too remarkable to be owing to chance, but I am ready to prove that it occurred without being foreseen or expected.

From all these results we may conclude, that one pound of sulphuric ether of the specific gravity 717 at the temperature of $16^{\circ}$ Reaumur, or of the same species with that employed by M. de Saussure, this liquid should have furnished in combustion enough of heat to raise to $180^{\circ} \mathrm{F}$. $\mathbf{8 2 . 3 6 9}$ pounds of water; viz.

That furnished by $\cdot 059$ pound of carbon 33.989 lbs.

And that furnished by $0.118 \mathrm{lb}$. of hydrogen $43 \cdot 386$

$82 \cdot 369$

If the proportion of free hydrogen in the ether analysed by $M$. de Saussure was really such as he has determined it to be, one pound of this liquid ought to furnish a sufficiency of heat in its combustion to raise to $180^{\circ}$ of Fahrenheit 113.566 pounds of water, viz. 
in Combustion, and in the Condensation of Vupours. 448

That furnished by 0.59 pound of carbon $33.989 \mathrm{lbs}$. And that which was furnished by 0.194091

o hydrogen ................... $79.5 \% 7$

113.566

But I can the less persuade myself that this hquid can furnish in its combustion so much heat, because one pound of white wax furnished no more than what was sufficient to heat $94 \cdot 682$ pounds of water to the same degree.

According to the analysis of M. de Saussure, 100 parts of sulphuric ether of the specific gravity of 717 at $16^{\circ}$ Reaumur are composed of

Carbon ................ 59 parts

Hydrogen............... 22

Oxygen $\ldots \ldots \ldots \ldots \ldots \ldots \ldots 19$

\section{0}

Supposing that the 19 parts of oxygen ate combined with $3 \cdot 6$ parts hydrogen, so as to form with them $21 \cdot 6$ parts water, 100 parts of this kind of ether ought to ne composed of Carbon................59

Free and combustible hydrogen.. 19.4

Consequently, inflammable substances $\overline{7 \cdot 4}$

Water ..................... $21 \cdot 6$

$$
100
$$

From the result of my experiments, 100 parts of this kind of ether ought to be composed of

Carbon................ 59

Free or combustible hydrogen ... 11.8

Consequently, combustible substances $70 \cdot 8$

IVater.................... $29 \cdot 2$

100

Or, reducing the water to its elements :

Carbon ..................... 59

Hydrogen, free or combustible . $11 \cdot 8$

Ditto, non-combustible ...... $3.5 \quad 15.3$

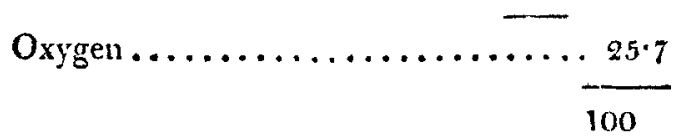

According to M. de Saussure's analysis as well as from the results of my experiments, 100 parts of pure alcohol of Lowitz, 


\section{Researches upon the Heat developed in Combustion.}

Lowitz, of the specific gravity of $79 \dot{4}$, at the temperature of $16^{\circ}$ Reaumur, are composed of

Carbon............... 42.82

Frce or combusible hydrogen ... 10.18

Consequently, combustible substances 53

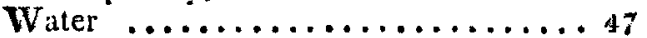

\section{0}

Or, reducing the water to its clements, 100 parts of this alcohol are composed of

Carbon .................. 42.82

Hydrogen, combined and noncombustible ........... 5.64

Hydrogen, combustible...... 10.18 15.82

Oxygen ..................41:56

100

By supposing that water exists completely formed both in alcohol and ether, the constituent parts of these two liquids would be, according to the results of our inquiries, Alcohol. Ether.

Carbon................42.82 59

Combustible hydrogen $\ldots \ldots \ldots \ldots 10.18 \quad 11.8$

Water ................47 29.2

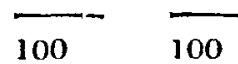

The elements of water exist most assuredly both in alcohol and ether; but there is good reason to believe that water does not exist in its natural state of condensation in these two substances, neither when they are in a state of liquidity, nor when, bcing sufficiently heated, they are transfurmed into elastic fluids.

When we mix water with alcohol, there is a considerable change both in temperature and volume, which indicates a new arrangement of elements, or a chemical action; and what proves in a still more certain manner that this action has taken place, the liquid which results from this mixture may be distilled, i.e. vaporized by heat, and afterwards condensed, without being decomposed : but it is above all in the litile heat which is developed in the condensation of the vapour of alcohol and ether that we discover certain proofs that the oxygen and hydrogen which exist as elements in these liquids do not exist in the state of water. I shall recur to this subject again. 